\title{
National Identity as Core Concept for the European Standardization Procedure
}

\author{
Stoica Elena \\ Doctoral Studies Institute, University of Economic Studies, Bucharest, Romania
}

Copyright $\bigcirc 2016$ by authors, all rights reserved. Authors agree that this article remains permanently open access under the terms of the Creative Commons Attribution License 4.0 International License

\begin{abstract}
It is known that the numerical expansion of the population and the diversity within the European Union (EU) change the complexity of the standardisation process. A socio-demographic analysis revealed the items frequently mentioned among the most important sources of European and National identities that have to be considered when standardize services. Another issue of the study is the fact that both the standardization process and the balance between National and European identities are in fact dynamic, changing over time. Starting with this paper, we can later explain how the globalization of economies influences the notion of National identity.
\end{abstract}

Keywords National Identity, Services Standardization, European Union, Internal Market

\section{Reasons of Slow Standardization}

Services sectors comprise a wide range of economic activities, from banking, education, IT and transport, to childcare, cleaning and hospitality. The freedom of services movement is one of the foundations of the single market replacing national and often conflicting standards - along with the freedoms of movement of persons, goods and capital. In one of these areas, respectively goods, the European standardization system has already made an important contribution, principally by means of the "New Approach" to legislation, designed to prevent the creation of technical barriers to trade.

The European Council of 4 February 2011 confirmed that standardization is a crucial framework condition to boost private investment in innovative services and that standardization processes should be accelerated, simplified and modernized. For that, the ESOs should reduce the average time to develop European standardization deliverables requested by the Commission (50\%) until 2020. In addition, the Regulation will streamline and shorten the procedure for objections to a harmonized standard.

Despite the increasing growth of the standardization provision role, standardization activity has been controlled towards local development, with the vast majority of service standards developed at national, rather than European level. In this situation we raise the question relating to the slow standardization process and the reason behind that. To offer pertinent answers, we decided to investigate also the impact of diverse national identity and the integrated migration process studies at the EU level.

\subsection{Standardization Provision Challenges a Top to Bottom Concept}

Services aren't tradable to the same degree as goods, but there is a growth potential while cross-border trade in services is increased. Methods for facilitating a greater level of cross-border trade in services might include national deregulation, EU harmonisation and standardisation. Service standards are also offering significant benefits in improving understanding and communication through common terminology. Service standards are also bringing important benefits by helping service providers to meet legislative or regulatory requirements.

As the past studies demonstrated, a majority of users indicate that they have seen improvements in their market share and profitability as a result of implementing service standards.

The role of services standards is to support the development of the single market for services as the Project $2020^{1}$ states and has been increasingly promoted and formally recognized by the European Commission in 2006, through its Directive on Services, as well as in other important legislation ${ }^{2}$. The revision of the European legislation on standardization has been elected as one of the 12 priority actions of the Single Market $\mathrm{Act}^{3}$. In order to avoid fragmentation of the market by proliferating national

1 A strategic vision for European standards: Moving forward to enhance and accelerate the sustainable growth of the European economy by 2020

2 COM (2011) 0206: Single Market Act, Proposal for a regulation on European standardization

3 COM/2011/0206: Single Market Act, Twelve levers to boost growth and strengthen confidence "Working together to create new growth", Point 2.5. 
service standards and to facilitate the cross-border provision of services, standardisation should be developed at European level, taking full account of market needs ${ }^{4}$. So, in 2013, to ensure that Europe's standardisation system can meet business' challenges, the Commission proposed a reform package ${ }^{5}$ including a new Regulation on European standardisation which took effect from 1 January 2013. This reform aimed at increasing the system's inclusiveness, speed, responsiveness, transparency, flexibility and scope.

Starting with this study, we can later explain how the globalization of economies influences the notion of National identity.

\section{Distinctive Approaches of Standardization Process}

During the period 1998-2004 almost a quarter (24\%) of the new service standards developed were at European (as compared to national) level, but more recently (2005-2011) this share has fallen to just $17 \%$.

A study made by Technopolis Group ${ }^{6}$ (2012) in the services area has identified a total of 55 full European standards and 380 full national standards. This is a relatively small number in comparison to the several thousand product standards developed at national and European levels over the past few decades.

The same study has identified 163 relevant certification schemes, which are operated by 41 different Certification Bodies based in 17 different countries. The 163 schemes collectively cover 111 different service standards, or $26 \%$ of those identified through the study. Based on these results we can say that around one in four of the national and European service standards developed appear to have certification schemes linked to them. A higher proportion of the European service standards have linked certification schemes $(44 \%)$ as compared to national service standards $(23 \%)$.

Seven times as many service standards exist at national level within the 32 countries $(n=380)$, analysed by Technopolis Group, as compared to European service standards $(\mathrm{n}=55)$. A high proportion $(86 \%)$ of the schemes is linked to just one standard. A further $10 \%$ of the schemes are linked to two standards, and the remaining $4 \%$ of schemes are linked to between three and seven standards.
The standards with schemes have to cover the same ground as each other in order to trade the services in the countries affected. Due to the existence of the standards and schemes, traders are countering market barriers.

Currently adopted European standards appear more likely to lead to the development of certification schemes $(40 \%$ of cases) than do currently adopt national standards $(23 \%$ of cases).

Of the 28 European Union countries, France, Italy, Austria and Spain have developed the largest number of national service standards (40 each), while Belgium, Croatia, Luxembourg, Poland, Bulgaria, and Slovenia have yet to develop any standards in the field of services.

The study made by Technopolis in $2012^{7}$ revealed a number of barriers to the use of standards. Respondents used in the study suggested that because of the detailed, technical nature of the text and the complexity of the language and vocabulary used standards were prohibitive to their use.

\section{National Identities and Globalization}

Literature on "national identity" is vast, but the background is developed mainly from only one side, with a lack of global vision and a need of series of historical case studies focus on interrelated areas: ethnic communities, tendencies in education and communication, geopolitical changes, national structures, uniformity and continuity elements, national myths and legends.

In contemporary literature, Smith (1992) locates the origins of modern nations in pre-modern culture (ethnies) and underline that nations emerge out of pre-existing ethnic groups. He considered that each ethnic group should have, at least, a myth of common ancestry, shared historical memories, a collective name, and an association with a specific territory. Smith sees symbols playing particular importance to identity. National identity is built through specific social dramas and events in which the meaning of the nation is contested and potentially transformed. Cultural differences can be seen also inside a nation, but in this case we consider nation as a cultural homogeneous area, with one national identity representation in material symbols, in rituals that succeed taking hold the national culture (Sewell, 1999).
4 Regulation 1025/2012/EU of the European Parliament and of the Council of 25 October 2012 on European standardisation OJ L 316/12

$5 \operatorname{COM}(2014)$ 500: „The annual Union work programme for European standardisation for 2015 "

6 James Stroyan and Neil Brown: A study on services certification linked to service standards at national level in Europe, Nordic Innovation Report 2012
7 James Stroyan and Neil Brown: "Services Study on the implementation of service standards and their impact on service providers and users", 2012, Technopolis Group 


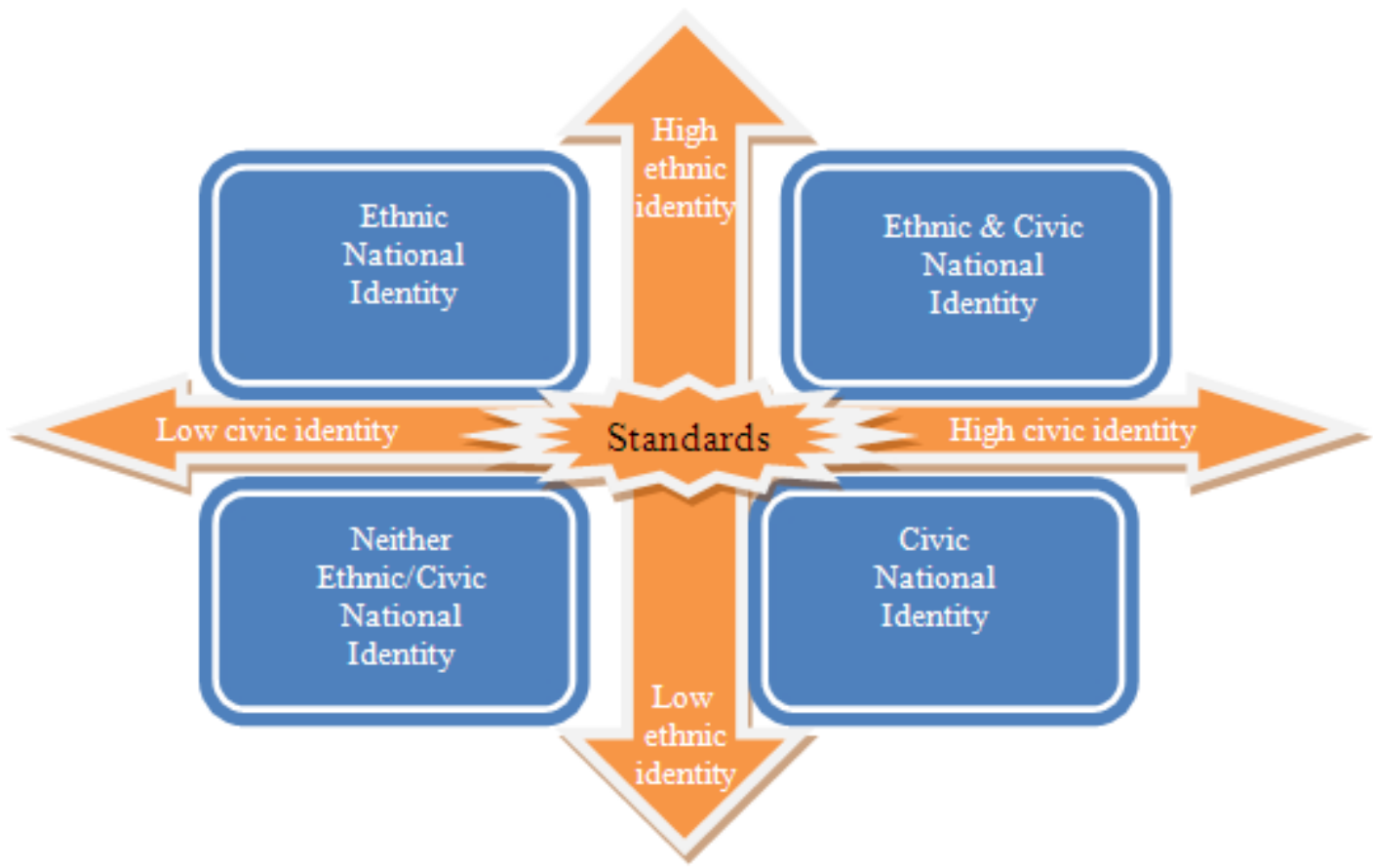

Figure 1. The two dimensions of national identity $($ Cohen,1994) and the standardization policy

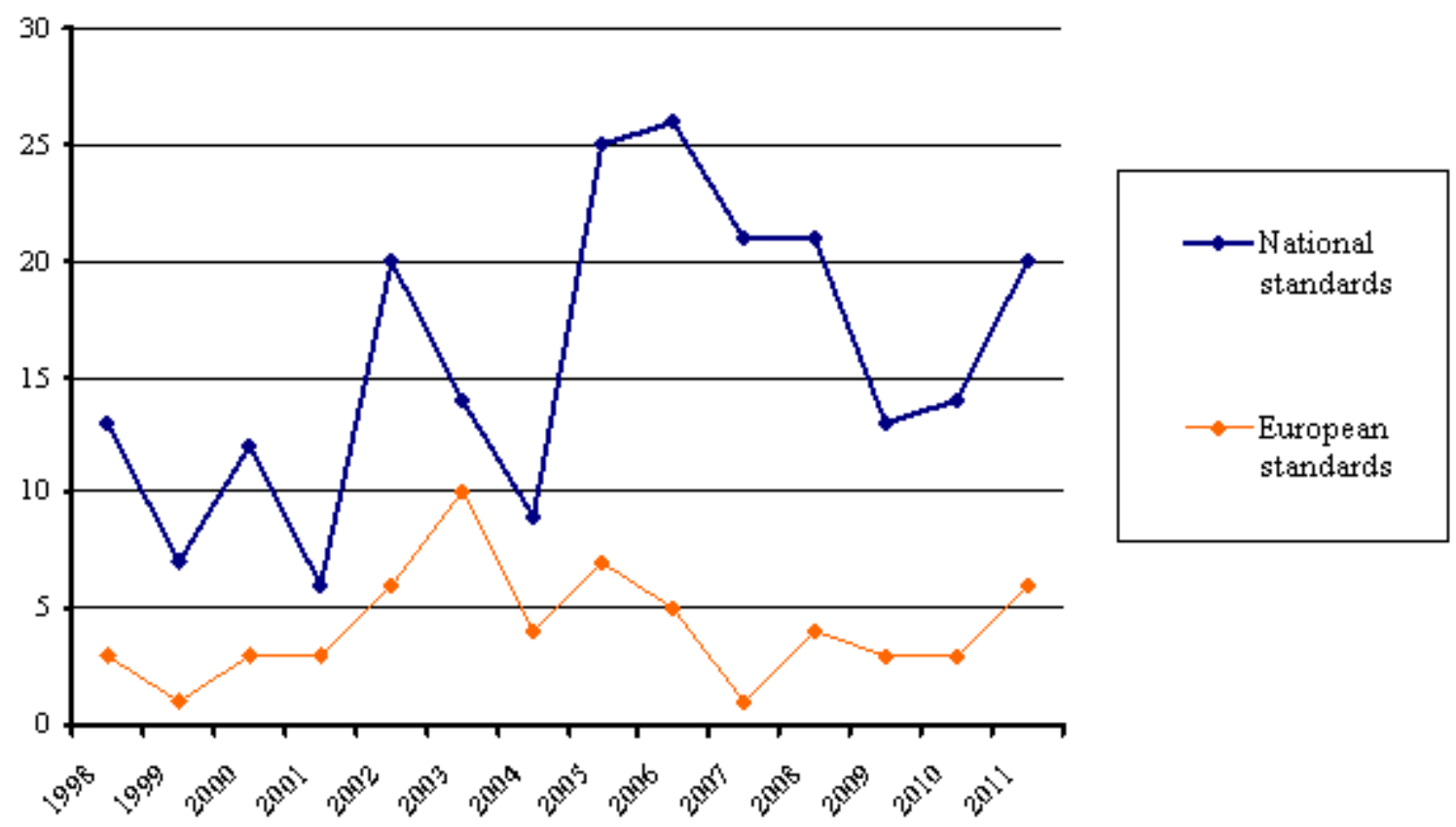

Figure 2. Comparing national and European published standards by year of publication 


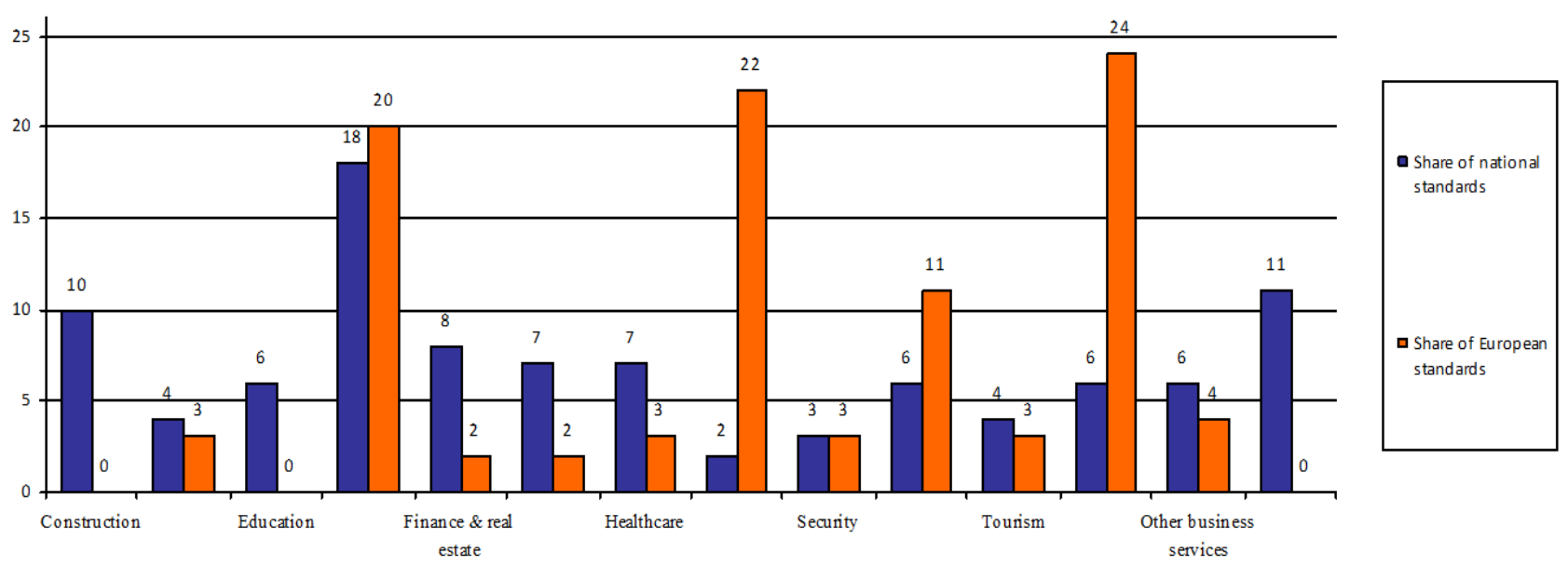

Figure 3. Share of national and European standards

Table 1. Areas of harmonized services and affected by certification schemes

\begin{tabular}{|c|c|c|c|c|c|}
\hline \multicolumn{2}{|c|}{$\begin{array}{c}\text { Main } \\
\text { domains }\end{array}$} & $\begin{array}{l}\text { Services with a high ratio of } \\
\text { National to European }\end{array}$ & \multicolumn{2}{|c|}{$\begin{array}{l}\text { Services with a low number } \\
\text { of certification schemes }\end{array}$} & $\begin{array}{c}\text { Services with a high number of } \\
\text { certification schemes }\end{array}$ \\
\hline \multicolumn{2}{|c|}{ Construction and utilities } & $\mathrm{X}$ & \multicolumn{2}{|c|}{$\mathrm{X}$} & - \\
\hline \multicolumn{2}{|c|}{ Customer contact } & - & \multicolumn{2}{|c|}{-} & $\mathrm{X}$ \\
\hline \multicolumn{2}{|c|}{ Education, training and recruitment } & $\mathrm{X}$ & \multicolumn{2}{|c|}{-} & - \\
\hline \multicolumn{2}{|c|}{ Facilities \& maintenance } & - & \multicolumn{2}{|c|}{$\mathrm{X}$} & - \\
\hline \multicolumn{2}{|c|}{ Finance \& real estate } & $\mathrm{X}$ & \multicolumn{2}{|c|}{-} & - \\
\hline \multicolumn{2}{|c|}{ Food \& accommodation } & $\mathrm{X}$ & \multicolumn{2}{|c|}{-} & - \\
\hline \multicolumn{2}{|c|}{ Healthcare \& personal services } & $\mathrm{X}$ & \multicolumn{2}{|c|}{-} & - \\
\hline \multicolumn{2}{|c|}{ IT, information \& communication } & - & & & - \\
\hline Security & gency & - & & & $\mathrm{X}$ \\
\hline Spor & & - & & & - \\
\hline & & - & & & $\mathrm{X}$ \\
\hline Transp & istic & - & & & $\mathrm{X}$ \\
\hline $\mathrm{Crc}$ & & - & & & - \\
\hline Country & $\begin{array}{l}\text { National } \\
\text { standards }\end{array}$ & $\begin{array}{c}\text { National certification } \\
\text { scheme }\end{array}$ & Country & $\begin{array}{l}\text { National } \\
\text { standards }\end{array}$ & $\begin{array}{c}\text { National } \\
\text { certification scheme }\end{array}$ \\
\hline Austria & 44 & 19 & Italy & 45 & 6 \\
\hline Belgium & 0 & 0 & Latvia & 14 & 1 \\
\hline Bulgaria & 0 & 0 & Lithuania & 2 & 0 \\
\hline Croatia & 0 & 0 & Luxembourg & 0 & 0 \\
\hline Cyprus & 1 & 0 & Malta & 5 & 4 \\
\hline Czech Republic & 0 & 0 & Netherlands & 6 & 11 \\
\hline Denmark & 2 & 4 & Poland & 0 & 0 \\
\hline Estonia & 16 & 1 & Portugal & 20 & 0 \\
\hline Finland & 1 & 0 & Romania & 9 & 0 \\
\hline France & 78 & 30 & Slovakia & 4 & 6 \\
\hline Germany & 12 & 13 & Slovenia & 0 & 0 \\
\hline Greece & 6 & 4 & Spain & 40 & 25 \\
\hline Hungary & 7 & 2 & Sweden & 2 & 0 \\
\hline Ireland & 4 & Uni & nited Kingdom & 17 & 28 \\
\hline
\end{tabular}

On the other hand, many studies see the national identity in various dimensions: territorial boundary of separate cultural populations; the nature of myths of origin and historical memories; a mass standardized culture; a unified system of common legal rights.

Modernist such as Ernest Gellner (1964) considers that nations are socially constructed by those in authority, to serve a specific purpose, generally to modernise the 
economy and society. Part of the process, Gellner argues, is that symbols were and continue to be manipulated to gain the support of the masses. Roger Brubaker (1992) speaks about one's nation that shapes the institutional realities of statehood inform immigration policies, and affect integration practices.

Some contemporary theories tell that there are signs of a kind of fear of what might be called "placelessness" signifying a loss of roots in this globalizing world. What might be called "hybrid identities" arise from international migration. This is increasingly a global phenomenon. People may define themselves by the place of origin of their ancestors, identifying perhaps as Turkish Germans or Syrian Greeks. An identity with other nations beyond one's country of residence is called "transnational identity" (Airriess and Miyares 2007). The authors demonstrate that more recent immigrants are generally more likely to retain stronger contact with their places of origin through remittances and still-active migration chains. Among immigrant groups that have been in a host country for generations, transnational identity becomes more of an occasional nostalgic gesture (Hawkins, 2007).

To conclude, Ernest Renan underlines the three things that constitute the spiritual principle of the unity of a nation: “. . . the possession in common of a rich legacy of memories ... the desire to live together, [and] the will to perpetuate the heritage that one has received in an undivided form"(Renan, 1990).

\subsection{Strategy to Redefine Europeans}

As literature tells us, there are several conditions that may cause national identity to come into conflict with European identity. Factors such as economic decline, migration, etc., can bring about such re-evaluations of identities. The other category of arguments suggests that European identity can be constructed and can function alongside national identities, because their markers of cohesiveness are different. While national identities are based on perceived primordial allegiances and are enforced by shared cultures and history, attachment to the European Union is based on what Habermas (2001) calls "constitutional patriotism".
A comparison made by Eurobarometer refers to the sense of European citizenship compared with national citizenship ${ }^{8}$ and shows that a majority of respondents continue to see themselves as European citizens. However, almost four out of ten Europeans define themselves solely by their nationality (39\%). A majority of respondents define themselves only by their nationality in three Member States: the United Kingdom (58\%), Greece (53\%) and Cyprus (51\%). In Bulgaria, identical proportions of respondents define themselves solely by their nationality $(49 \%)$ and as citizens of the EU (49\%).

Attachment to country (90\%) is far more important than attachment to the EU, as the Fig.5 illustrates. Although the feeling of attachment to the EU is still less marked, it has now crossed the absolute majority threshold at $51 \%$. At national level it has increased, in 23 Member States in one year, especially in Lithuania ( +14 points), Finland $(+13$ points), the Netherlands ( +12 points) and Belgium and the United Kingdom ( +10 points). There is a difference of 52 percentage points between the countries most and least attached to the EU. Those least likely to say they are attached to the EU are in Cyprus (22\%), Greece (29\%) and the United Kingdom (33\%).

On the other hand, national identities are still dominant in Europe. The main distinguishing characteristics of the EU from the nation-state are the absence of a shared language, a uniform media, common education system and a central state structure. Surveys show that, people in Europe prefer maintaining their national identity and sovereignty, but increasing number of people has European identity in addition to their national identities.

Although individuals may have multiple identities, specific contexts and circumstances dictate which identity becomes more important at a particular time. The nature of the relationship between different identities is dictated by the categories those identities belong to. One can distinguish between contrasting and non-contrasting identities: the first type accounts for the identification with groups belonging to the same category, while the latter refers to groups belonging to different categories (Sen, 2007). 


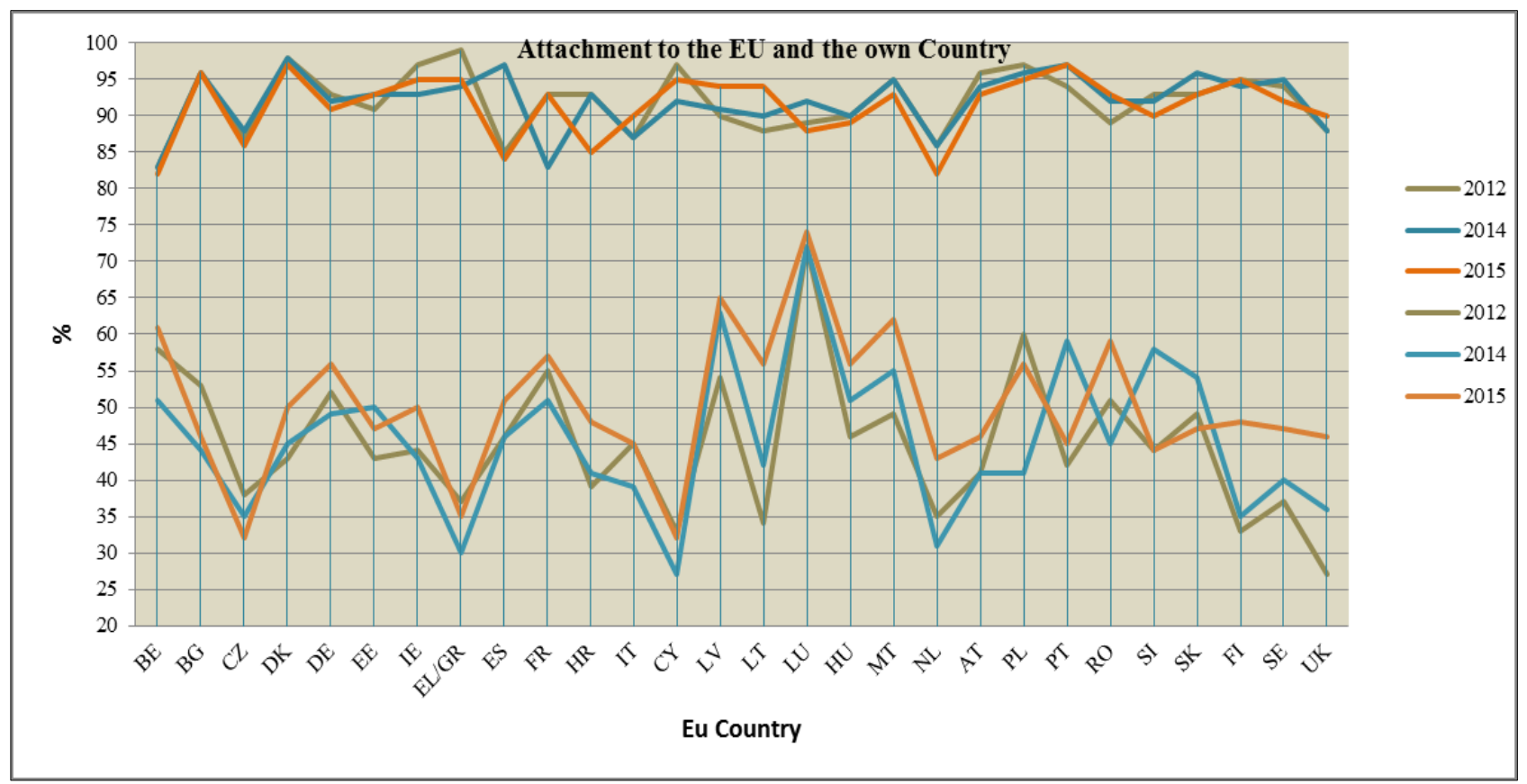

Figure 5. The sense of national citizenship compared with national citizenship (Eurobarometer 82,84)

\section{Data Overview}

The success of European integration is often questioned by the high level of cultural diversity. This was debated before the last enlargement in particular, when the EU grew from 15 to 25 and shortly after to 27 member states. With the above approach, the developments in the level of diversity through language, ethno-racial, and religious characteristics, can easily be traced.

The study uses Greenberg's (1956) index of cultural diversity, GI that measures cultural similarity between ethnic groups. A crucial point in assigning cultural distances to groups is the specification of the resemblance factors rij.

Greenberg's (1956) index of cultural diversity, GI, has the following form:

$$
G I=1-\sum_{i=1}^{G} \sum_{i=1}^{G} p_{i} p_{j} r_{i j}
$$

where pi and pj refer to the respective proportions of groups $\mathrm{i}$ and $\mathrm{j}$ in the particular country's population. The resemblance between groups $i$ and $j$ is captured by the factor rij, which is restricted between 0 and 1 (where a value of 1 means full cultural similarity between the two groups). The idea behind this functional form is that from two geographical regions with the same population share, the one with the lowest resemblance across groups should exhibit the highest measure of diversity. It can be shown that if the resemblance between all groups is 0 , then GI exactly equals the widely used Herfindahl-based ethnic fractionalisation measure. An important feature of the Greenberg index is that one could also use disaggregated data of population shares and let the resemblance factors decide the degree to which different ethnic groups are merged.

\subsection{The Matrix of Services}

Bradley (1995) believes that some services are highly culture-bound and demand will be strongly influenced by the culture of the society. He places medical services, personal care, education programmes, films, video and selected advertising in this category. He considers banking services, computer software, some medical services and professional services as not so affected by national culture. Bradley links the cultural effects with scale effects which might be available to service companies. This gives him a four sector matrix as below: 


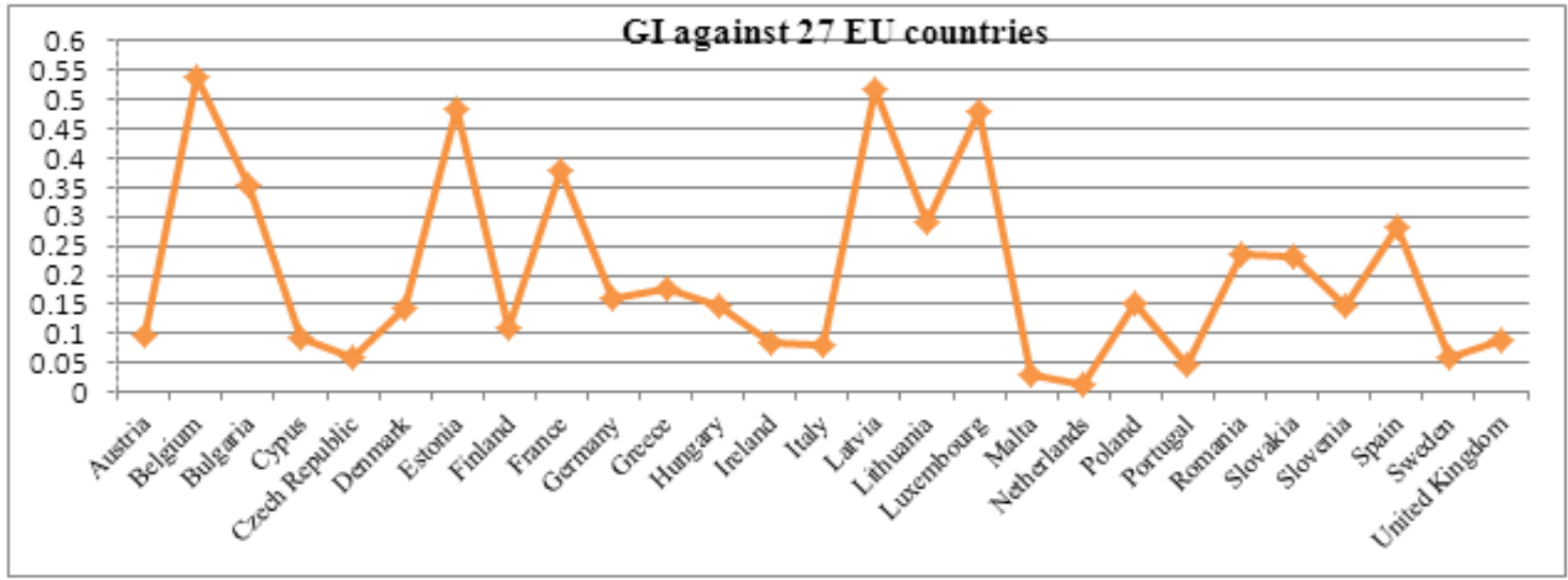

Figure 6. Cultural index differences across $27-$ EU countries

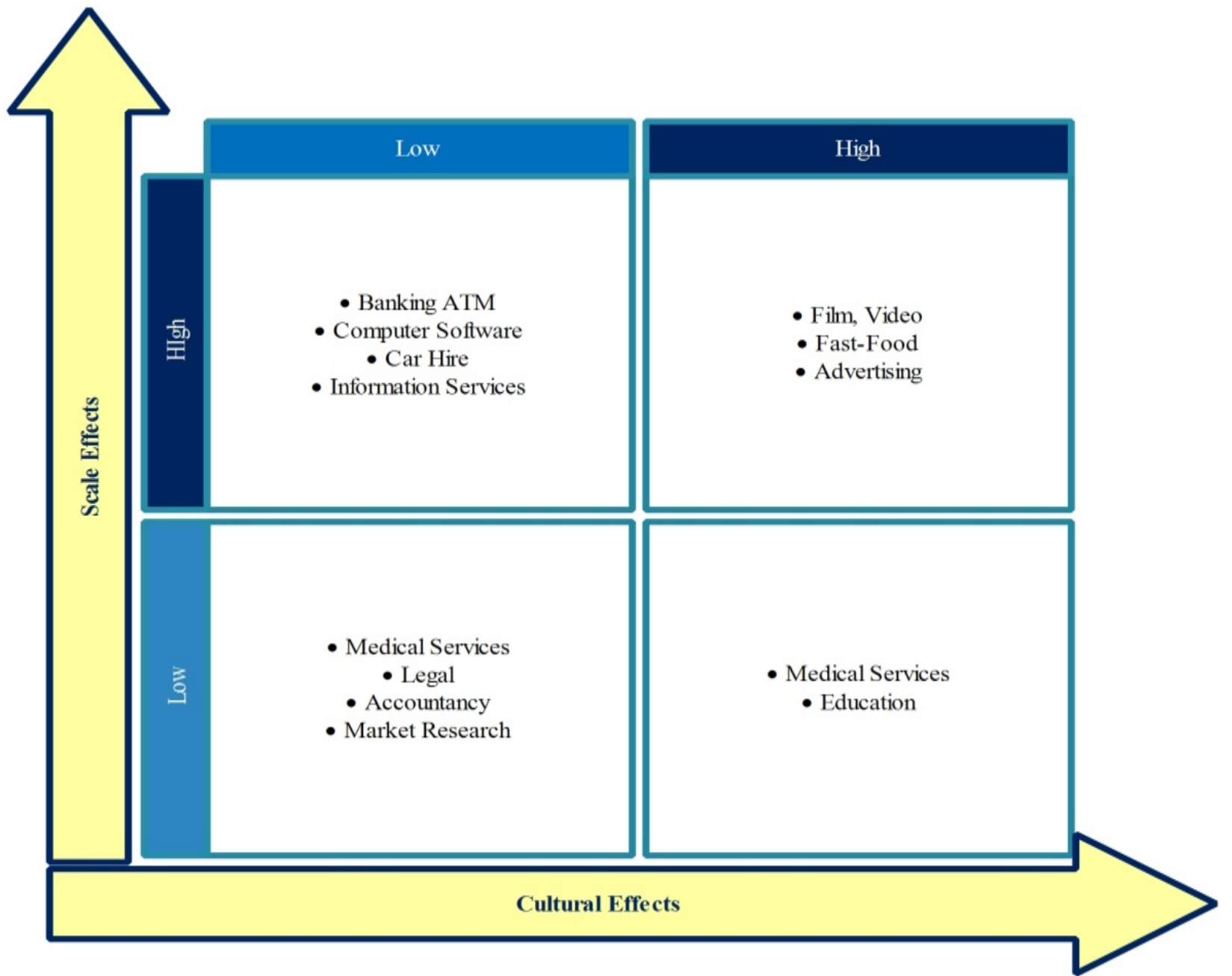

Figure 7. Services affected by culture

The notion of services being more culturally bound than others is not new. Quelch \& Hoff (1986) who talk about some products in general being more culturally attached than others, specially food products. But McDonald's which is available in 54 countries (Leidner, 1993) might provide the contrary. In other words, establishing the culturally bound nature of a product or service is difficult, but necessary for standarization. Usunier (1996) identifies that consumption is closely related to lifestyles and culture, and he recognises evidence which suggests that cultural bonds tend to be strong in the consumer goods sector. 
Table 4. Descriptive statistics for countries

\begin{tabular}{|c|c|c|c|c|c|c|c|}
\hline & \multicolumn{3}{|c|}{ Attachment to the country } & \multicolumn{2}{c|}{ Attachment to the EU } & \multicolumn{2}{c|}{ GI } \\
\hline & 2012 & 2014 & 2015 & 2012 & 2014 & 2015 & 2012 \\
\hline Standard Error & 0.812 & 0.7550 & 0.816 & 1.843 & 1.956 & 1.793 & 0.033 \\
\hline Median & 93 & 92.5 & 93 & 44 & 44.5 & 48 & 0.19 \\
\hline Mode & 93 & 92 & 93 & 43 & 51 & 56 & 0.26 \\
\hline Standard Deviation & 4.295 & 3.995 & 4.316 & 9.752 & 10.348 & 9.490 & 0.175 \\
\hline Sample Variance & 18.444 & 15.962 & 18.624 & 95.111 & 107.074 & 90.053 & 0.031 \\
\hline Range & 16 & 15 & 15 & 45 & 45 & 42 & 0.74 \\
\hline Minimum & 83 & 83 & 82 & 27 & 27 & 32 & 0.04 \\
\hline Maximum & 99 & 98 & 97 & 72 & 72 & 74 & 0.78 \\
\hline Largest(1) & 99 & 98 & 97 & 72 & 72 & 74 & 0.78 \\
\hline Smallest(1) & 83 & 83 & 82 & 27 & 27 & 32 & 0.04 \\
\hline Confidence Level(95.0\%) & 1.665 & 1.549 & 1.673 & 3.782 & 4.012 & 3.680 & 0.068 \\
\hline
\end{tabular}

Table 4. Study on correlation between variables

\begin{tabular}{|c|c|c|c|c|c|c|c|}
\hline & GI & EU 2012 & EU 2014 & EU 2015 & C2012 & C2014 & C2015 \\
\hline GI & 1 & 0.175684653 & 0.205086171 & $\mathbf{0 . 3 1 8 8 6 6 8 5 9}$ & $\mathbf{- 0 . 4 1 4 6 8 9 8 3}$ & $\mathbf{- 0 . 3 1 6 3 1 5 6 6}$ & $\mathbf{- 0 . 4 0 6 3 8 8 1 2}$ \\
\hline $\begin{array}{c}\text { National } \\
\text { standards }\end{array}$ & -0.13151884 & 0.077171819 & 0.058865336 & 0.04825042 & -0.13598885 & $\mathbf{- 0 . 3 0 3 4 0 0 0 1}$ & -0.00538133 \\
\hline $\begin{array}{c}\text { National } \\
\text { certification }\end{array}$ & -0.01948181 & -0.11338515 & -0.11141516 & -0.00462405 & -0.16783708 & $\mathbf{- 0 . 2 5 7 9 9 7 5 2}$ & -0.18708918 \\
\hline
\end{tabular}

Pearson's correlation coefficient:

$\mathrm{r}=+/-0.5$ large effect size

$\mathrm{r}=+/-0.3$ medium effect size

$\mathrm{r}=+/-0.1$ small effect size

\subsection{The Rezulting Effect}

Past works on cultural diversity and economy underline the impact of diversity on the economic development of a country. Several econometric studies have established a clear connection at a macroeconomic level between standardisation in the economy, productivity growth, trade and overall economic growth. In general, the estimated effect of cultural diversity in this empirical specification means that a one-standard deviation increase in cultural diversity would decrease per capita income growth by about $16.10 \%$ (Goren, 2013) of its standard deviation. Further work is needed to explain the concrete mechanisms by which cultural diversity of a countries affects economic development in general. Also, the economic benefit of standardisation can vary significantly between different EU countries. Studies show that the impact of standards on annual GDP growth could rage from 0.3 to 1 percentage point. For Germany this impact is estimated at $1 \%$ of the gross national product, for France at $0.8 \%$ and for United Kingdom only at $0.3 \%$. But cultural diversity is an important explanatory variable in cross-country growth regressions. Therefore, further research should investigate the link between countries' diversity, attachment the country and the level of standardization.

\section{Results and Future Research}

\subsection{Study on Correlation and Conclusions}

9 Communication from the Commission to the European Parliament, the Council and the European Economic and Social Committee: "A strategic vision for European standards: Moving forward to enhance and accelerate the sustainable growth of the European economy by 2020"; Brussels, 1.6.2011 COM(2011) 311 final
In the European Union, ethnic and cultural diversity, but also pluralism of values and ways of living are increasing and the same seems to gradually, even though asymmetrically, apply for the neighbouring countries.

Since cultural diversity and ethnic fractionalization supposed to have negative impact on social cohesion and favor inequalities, it should be tested whether those can have impact also on standardization process.

It has not been statistically tested whether and what kind of correlation can be made among these different variables, but the simply correlation between the cultural index and the feeling of attachment is a good approach to test the hypothesis of cultural diversity effects.

As the descriptive statistics in Table 4 shows, all variables have reasonable data: mean values are what can be reasonably expected and no extreme minimum or maximum values exist. Serial correlation for that data is easily explained by intuition. By construction, the European Union creates interdependence between its countries, and thus it is indisputable that member countries exhibit correlation both between each other today and over time. As we can see on the table above, (but also in the Fig 5) the differences in median (2012-2015) is almost insignificant one year to another, ranging from 93.0 to 92.5 relating to the Attachment to the country and from 44 to 48 relating to Attachment to the EU.

The correlation matrix in Table 4 shows that not all associations are consistent with theoretical predictions, and few are statistically significant. The results of this analysis offer good evidence that there are no strong empirical backgrounds among all the seven analysed economic and social dimensions, most of these correlations being small, which reveals a very low degree of impact.

The widely accepted assumption that cultural diversity has 
negative impacts on institutional and economic performance, social cohesion, and economic policies is not confirmed.

The cultural diversity has a medium positive impact on attachment to the country $(+0.258)$, but also a medium correlation with attachment to the European Union $(+0.318)$. That means the national identity doesn't attract a negative trend in feeling attached to the European Union. Also, high national identity displays a medium effect towards standardization $(+0.303)$. As that table shows, there is a positive, but low association of migration with national certification schemes $(+0.258)$. The correlation above shows that the attachment to the EU doesn't affect in any way the standardization process.

To demonstrate the effectiveness of the European system, the Community needs a strong standards system at European level which is able to ensure that international standards, elaborated and transposed into European standards to support Community policies, are coherent with these policies. A diversified system based on many competing National Standards Bodies could never play such a role.

\subsection{Further Research}

A great deal of work remains to be done examining other measures of impact and also considering how different dimensions of economic and social variable are influence the standardization process. Alongside this, a broader range of immigration indicators should be examined.

It would seem prudent to maintain a periodic watch on the rate of development of national and European service standards, to ensure that any proliferation does not begin to introduce barriers to trade in services as a result of competing or conflicting requirements. This because of the rise of the number of certification schemes in the area of services.

Table 5. The most important variables used in study

\begin{tabular}{|c|c|c|c|c|c|c|c|c|}
\hline \multirow[b]{3}{*}{ BE } & \multicolumn{3}{|c|}{ Attachment to the country } & \multirow[b]{2}{*}{2012} & \multicolumn{2}{|c|}{ ttachment to the $\mathbf{E U}$} & \multicolumn{2}{|r|}{ GI } \\
\hline & 2012 & 2014 & 2015 & & 2014 & 2015 & 2012 & Rank \\
\hline & 83 & 83 & 82 & 58 & 51 & 61 & 0.46 & 4 \\
\hline BG & 96 & 96 & 96 & 53 & 44 & 46 & 0.25 & 12 \\
\hline $\mathbf{C Z}$ & 87 & 88 & 86 & 38 & 35 & 32 & 0.06 & 24 \\
\hline DK & 98 & 98 & 97 & 43 & 45 & 50 & 0.13 & 20 \\
\hline DE & 93 & 92 & 91 & 52 & 49 & 56 & 0.1 & 22 \\
\hline $\mathbf{E E}$ & 91 & 93 & 93 & 43 & 50 & 47 & 0.49 & 2 \\
\hline IE & 97 & 93 & 95 & 44 & 43 & 50 & 0.16 & 19 \\
\hline EL/GR & 99 & 94 & 95 & 37 & 30 & 35 & 0.05 & 25 \\
\hline ES & 85 & 97 & 84 & 46 & 46 & 51 & 0.26 & 9 \\
\hline FR & 93 & 83 & 93 & 55 & 51 & 57 & 0.25 & 13 \\
\hline HR & 93 & 93 & 85 & 39 & 41 & 48 & 0.18 & 16 \\
\hline IT & 87 & 87 & 90 & 45 & 39 & 45 & 0.04 & 26 \\
\hline CY & 97 & 92 & 95 & 33 & 27 & 32 & 0.36 & 7 \\
\hline $\mathbf{L V}$ & 90 & 91 & 94 & 54 & 63 & 65 & 0.44 & 5 \\
\hline $\mathbf{L T}$ & 88 & 90 & 94 & 34 & 42 & 56 & 0.26 & 10 \\
\hline $\mathbf{L U}$ & 89 & 92 & 88 & 72 & 72 & 74 & 0.48 & 3 \\
\hline HU & 90 & 90 & 89 & 46 & 51 & 56 & 0.18 & 17 \\
\hline MT & 95 & 95 & 93 & 49 & 55 & 62 & 0.43 & 6 \\
\hline NL & 86 & 86 & 82 & 35 & 31 & 43 & 0.78 & 1 \\
\hline AT & 96 & 94 & 93 & 41 & 41 & 46 & 0.1 & 23 \\
\hline PL & 97 & 96 & 95 & 60 & 41 & 56 & 0.04 & 27 \\
\hline PT & 94 & 97 & 97 & 42 & 59 & 45 & 0.04 & 28 \\
\hline RO & 89 & 92 & 93 & 51 & 45 & 59 & 0.26 & 11 \\
\hline SI & 93 & 92 & 90 & 44 & 58 & 44 & 0.17 & 18 \\
\hline SK & 93 & 96 & 93 & 49 & 54 & 47 & 0.29 & 8 \\
\hline FI & 95 & 94 & 95 & 33 & 35 & 48 & 0.13 & 21 \\
\hline SE & 94 & 95 & 92 & 37 & 40 & 47 & 0.19 & 14 \\
\hline UK & 88 & 88 & 90 & 27 & 36 & 46 & 0.19 & 15 \\
\hline
\end{tabular}




\section{REFERENCES}

[1] Airriess, C. A. and Miyares, I. M., (2007). Exploring contemporary ethnic geographies, in I. M. Miyares and C. A. Airriess, eds. Contemporary Ethnic Geographies in America, Rowman and Littlefield, Lanham, MD, pp. 1-26

[2] Bradley, F., (1995). The service firm in international marketing, Prentice Hall

[3] Brubaker, R., (1992). Nationhood and Citizenship in France and Germany, Harvard University Press, Cambridge, MA

[4] Cohen, R. (1994). Frontiers of Identity, The British and Others. London: Longman.

[5] De Haas, H., (2010). Migration and development. A theoretical perspective, Blackwell Publishing Ltd, London

[6] Ekberg, J., (1999). Immigration and the public sector. Income effects for the native population in Sweden. Journal of Population Economics, 12(3), pp. 411-430

[7] Gannon, M. \& Pillay, R., (2013). Understanding global cultures. Metaphorical journeys through 31 nations, clusters of nations, continents, and diversity", Sage, Los Angeles

[8] Gellner, E., (1964). Nationalism, in "Thought and Change”, University of Chicago Press, Chicago, pp.147-180

[9] Goren. E., (2013). Economic Effects of Domestic and Neighbouring Countries' Cultural Diversity

[10] http://www.etsg.org/ETSG2013/Papers/042.pdf

[11] Habermas, J., (2005). Old Europe, new Europe, core Europe: Transatlantic relations after the Iraq war, Verso Book, London

[12] Hojelid, S., (2001). European Integration and the Idea of European Identity: Obstacles and Possibilities", ECPR Joint Sessions Grenoble 2001, Workshop

[13] Hawkins, M., (2007). Ethnic festivals, cultural tourism, and pan-ethnicity, in "Contemporary Ethnic Geographies in America", I. M. Miyares and C. A. Airriess,, M.D.Lanham: Rowman and Littlefield, pp. 375-395.

[14] Loughlin, I., and Peters B.G. (1997). State traditions, administrative reform and regionalization, in M. Keating and Loughlin J.(eds.), The Political Economy of Regionalism, London, Routledge, pp. 41-62.

[15] Quelch, J. and \& Hoff, E., (1986). Customizing global marketing, Harvard Business Review, 1986, May

[16] https://hbr.org/1986/05/customizing-global-marketing

[17] Renan, E., (1882). Qu'est-ce qu'une nation? in J. Hutchinson and A. D. Smith, eds. 1994. "Nationalism", Oxford University Press, Oxford

[18] Sen, A., (2007). Identity and violence: the illusion of destiny, WW. Northon Company, New York

[19] Sewell, W.H., (1999). The Concept(s) of Culture, in "Beyond the Cultural Turn", in Bonnel, V.E., Hunt, L. University of California Press, Berkley, pp 35-60

[20] Smith, A., (1986). The Ethnic Origins of Nations, in National Culture, National Identity and the Culture(s) of the Nation, in Zubrzycki, G, 2010 (Ed.) Routledge, New York

[21] Smith, A., (1992). National Identity and the idea of European unity, prepared for Europe in the 1990s Forces for Change

[22] Ushunier, J-C. \& Lee, J.A., (1996). Marketing across cultures, Pearson 